\title{
Analisis Kinerja Sistem Proteksi Transformator Tenaga Berdasarkan Frekuensi Gangguan Di Gardu Induk 150KV Kalibakal
}

\author{
Irawan Adi Prastowo ${ }^{1}$, Winarso ${ }^{2}$, Arif Johar Taufiq ${ }^{3}$ \\ Program Studi S1 Teknik Elektro, Universitas Muhammadiyah Purwokerto \\ Fakultas Teknik dan Sains, Universitas Muhammadiyah Purwokerto
}

\section{Informasi Makalah}

Dikirim, 22 Agustus 2019

Direvisi, 27 November 2019

Diterima, 6 Januari 2020

Kata Kunci:

Transformator

Sistem Proteksi

Kinerja Relai

Gangguan

\section{Keyword: \\ Transformer \\ Protection System \\ Relay Performance \\ Interference}

\section{INTISARI}

Untuk melindungi transformator tenaga di Gardu Induk $150 \mathrm{KV}$ Kalibakal dari kerusakan, maka dilakukan pemasangan relai proteksi yang dapat mengenal kondisi abnormal pada sistem tenaga listrik dan melakukan langkah-langkah yang dianggap perlu untuk menjamin pemisahan gangguan dengan kemungkinan gangguan terkecil terhadap operasi normal. Penelitian ini menganalisis keandalan kerja relai proteksi, sehingga sistem proteksi bekerja sesuai dengan fungsinya sebagai pengaman agar stabilitas tenaga listrik berlangsung dengan baik. Berdasarkan hasil penelitian ditemukan gangguan sebanyak 8 kali diantaranya gangguan teknis pada trafo 1 yang mengaktifkan relai OCR dan PMT karena arus beban melebihi arus nominal sebesar 875A, sedangkan arus nominal didapat 384,9A, pada trafo II terjadi gangguan hubung singkat karena feeder KBL I terbakar dengan lonjakan arus sebesar 3617A sedangkan arus nominalnya $577 \mathrm{~A}$ dan pada trafo III terjadi gangguan dengan arus gangguan sebesar 960A sedangkan arus nominalnya 230A dan mengakibatkan relai bucholz aktif. Dengan menggunakan rumus analisis deskripsi persentase maka didapatkan keandalan relai proteksi untuk melindungi transformator sebesar $91,67 \%$.

\footnotetext{
ABSTRACT

To protect the power transformer at the Kalibakal $150 \mathrm{KV}$ substation from damage, protective relays are installed that can recognize abnormal conditions in the electric power system and take steps deemed necessary to ensure the separation of faults with as little interference as possible during normal operation. This study analyzes the reliability of relay protection work, so the protection system works in accordance with its function as a safety device so that the stability of the electric power runs well. Based on the results of the study found 8 times the interruption including technical interference on transformer 1 that activates OCR and PMT relays because the load current exceeds the nominal current of $875 \mathrm{~A}$, while the nominal current is obtained 384.9A, in transformer II there is a shortage of circuit disruption due to combustion of the KBL I feeder with the inrush current is $3617 \mathrm{~A}$ while the nominal current is $577 \mathrm{~A}$ and in transformer III there is interference with the fault current 960A while the nominal current is $230 \mathrm{~A}$ and produces an active bucholz relay. Using the percentage description analysis formula, the reliability of the relay protection to protect the transformer is $91.67 \%$.
} 


\title{
Korespondensi Penulis:
}

\author{
Irawan Adi Prastowo \\ Program Studi Teknik Elektro \\ Fakultas Teknik dan Sains Universitas Muhammadiyah Purwokerto \\ JL. Raya Dukuhwaluh, Purwokerto, 53182 \\ Email: irawanadhi97@gmail.com
}

\section{PENDAHULUAN}

Gardu Induk pembangkit merupakan suatu sistem Instalasi listrik yang terdiri dari beberapa peralatan listrik dan menjadi penghubung listrik dari Pembangkit ke jaringan transmisi yang selanjutnya disalurkan ke jaringan distribusi primer, dan berfungsi sebagai penyalur daya dengan kapasitas KVA, MVA sesuai dengan tegangan operasinya. Gardu induk merupakan salah satu bagian dari sistem tenaga listrik yang mempunyai kemungkinan sangat besar rmengalami bahaya yang disebabkan oleh timbulnya gangguan dari petir maupun arus lebih sehingga arus gangguan itu mengalir ke tanah sebagai akibat isolasi peralatan yang tidak berfungsi dengan baik [1].

Salah satu komponen utama pada gardu induk yaitu trafo tenaga yang merupakan peralatan penting dalam penyaluran tenaga listrik, karena trafo merupakan peralatan yang menyalurkan energi listrik langsung ke konsumen baik konsumen tegangan tinggi, tegangan menengah, maupun tegangan rendah. Untuk melindungi trafo tenaga dari kerusakan, telah dilakukan pemasangan relai proteksi yang dapat mengenal kondisi abnormal pada sistem tenaga listrik dan melakukan langkah-langkah yang dianggap perlu untuk menjamin pemisahan gangguan dengan kemungkinan gangguan terkecil terhadap operasi normal. Hal yang dilakukan untuk mengatasi gangguan-ganguan tersebut adalah inspeksi, melakukan perhitungan dan analisis untuk menentukan kehandalan relai, sehingga sistem proteksi bekerja sesuai dengan fungsinya sebagai pengaman agar stabilitas tenaga listrik berlangsung dengan baik [2].

Untuk mengetahui kuantitas gangguan dan kinerja sistem proteksi dalam mengamankan suatu peralatan Gardu Induk maka peneliti perlu melakukan penelitian dan analisa perhitungan dari kuantitas gangguan dan kinerja sistem proteksi dengan metode deskriptif analisis dan dengan studi kasus penelitian di Gardu Induk 150KV Kalibakal [3].

\section{METODE PENELITIAN}

\subsection{Waktu dan Tempat Penelitian}

Penelitian dilakukan selama tiga minggu mulai tanggal 1-22 Mei 2019 pada sistem proteksi transformator tenaga Gardu Induk 150KV Kalibakal.

\subsection{Prosedur Penelitian dan Analisis}

\section{a. Teknik Pengambilan Data}

Data kinerja Sistem Proteksi pada transformator tenaga dan data gangguan yang sering terjadi pada transformator tenaga di Gardu Induk $150 \mathrm{KV}$ Kalibakal. 
Langkah penelitian seperti pada Gambar 1.

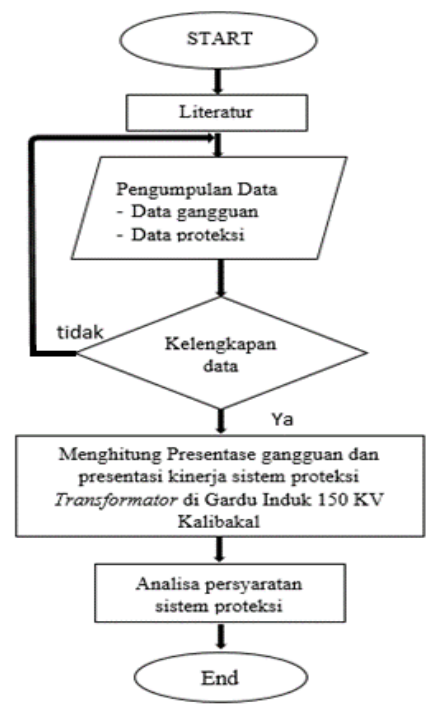

Gambar 1. Diagram Alir Penelitian (Flow Chart)

\section{b. Analisis}

Berdasarkan dari data-data yang di peroleh tentang gangguan yang terjadi di Gardu Induk 150KV Kalibakal kemudian dianalis dengan metode analisis deskriptif persentase. Dimana metode deskriptif persentase untuk memberi deskripsi atau pembahasan dari hasil penelitian yang dilakukan yang masih bersifat data kuantitatif sehingga diperoleh gambaran kualitatif dari hasil penelitian. Dalam penelitaian ini rumus yang dipergunakan adalah:

1. Menghitung Persentase Gangguan

Deskripsi persentase gangguan pada sistem proteksi trafo tenaga di gardu induk sesuai rumus berikut [5].

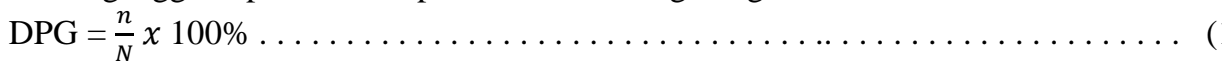

Keterangan:

$\begin{array}{ll}\mathrm{DPG} & =\text { Deskripsi persentase gangguan }(\%) \\ \mathrm{n} & =\text { Fekuensi gangguan }(\text { kali) } \\ \mathrm{N} & =\text { Jumlah gangguan (kali) }\end{array}$

2. Menghitung persentase keandalan relai

Deskripsi persentase keandalan/keberhasilan sistem proteksi trafo tenaga dalam menangani gangguan di gardu induk sesuai rumus berikut [5].

$$
\mathrm{DPK}=\frac{n}{N} \times 100 \%
$$

Keterangan:

$$
\begin{array}{ll}
\mathrm{DPK} & =\text { Deskripsi persentase keandalan relai }(\%) \\
\mathrm{n} & =\text { Kinerja relai }(\text { kali }) \\
\mathrm{N} & =\text { Jumlah gangguan relai }(\text { kali })
\end{array}
$$

Halaman Web JRRE : http://jurnalnasional.ump.ac.id/index.php/JRRE 
Keandalan relai dikatakan cukup baik bila mempunyai hari dari 90\% sampai dengan 99\%. Dari hasil penelitian yang dilakukan data gangguan dan kinerja dari sistem proteksi pada gardu induk $150 \mathrm{KV}$ Kalibakal dari tahun 2012-2017 akan di deskripsikan dalam bentuk persentase.

\section{HASIL DAN PEMBAHASAN}

Banyaknya gangguan yang terjadi pada trafo tenaga Gardu Induk $150 \mathrm{KV}$ Kalibakal tahun 2012 - 2017.

Tabel 1. Gangguan pada Sistem Proteksi Area Trafo Tenaga Gardu Induk 150 KV Kalibakal Tahun 2012-2017.

\begin{tabular}{lccccc}
\hline & & \multicolumn{3}{c}{ Penyebab Gangguan } & Frekuensi \\
\cline { 3 - 5 } No & Tahun & Teknis & Non teknis & $\begin{array}{c}\text { Tidak } \\
\text { Diketahui }\end{array}$ & Gangguan \\
\hline $\mathbf{1}$ & 2012 & 3 & - & - & 3 \\
$\mathbf{2}$ & 2013 & 2 & - & - & 2 \\
$\mathbf{3}$ & 2014 & - & - & - & - \\
$\mathbf{4}$ & 2015 & - & - & - & 1 \\
$\mathbf{5}$ & 2016 & 1 & - & - & 1 \\
$\mathbf{6}$ & 2017 & 1 & - & & 8
\end{tabular}

(Sumber: Gardu Induk Kalibakal, 2019) Kalibakal.

Perhitungan persentase frekuensi gangguan yang terjadi di area Trafo Tenaga Gardu Induk $150 \mathrm{KV}$

Tabel 2. Persentase Gangguan pada Sistem Proteksi Area Trafo Tenaga Gardu Induk 150 KV Kalibakal Tahun 2012-2017

\begin{tabular}{cccc}
\hline \multirow{2}{*}{ No } & Tahun & Frekuensi Gangguan & Presentase Gangguan \\
\cline { 3 - 4 } & 2012 & Kali & $\%$ \\
$\mathbf{1}$ & 2013 & 3 & $37,5 \%$ \\
$\mathbf{3}$ & 2014 & 2 & $25 \%$ \\
$\mathbf{4}$ & 2015 & - & - \\
$\mathbf{5}$ & 2016 & 1 & $12,5 \%$ \\
$\mathbf{6}$ & 2017 & 1 & $12,5 \%$ \\
& Jumlah & 1 & $12,5 \%$ \\
\hline
\end{tabular}

Banyaknya berbagai gangguan di Gardu Induk 150kV Kalibakal dari tahun 2012-2017 maka diminimalisir dengan sistem proteksi untuk menimalisir terjadinya gangguan pada area trafo dapat dilihat pada Tabel 3.3 berikut. 
Tabel 3. Sistem Proteksi Area Trafo Tenaga Gardu Induk 150 KV Kalibakal 2012-2017

\begin{tabular}{lcccc}
\hline \multirow{2}{*}{ No } & \multirow{2}{*}{$\begin{array}{c}\text { Relai Proteksi Trafo } \\
\text { Tenaga }\end{array}$} & $\begin{array}{c}\text { Kampu } \\
\text { Mengamankan }\end{array}$ & $\begin{array}{c}\text { Tidak Mampu } \\
\text { Mengamankan }\end{array}$ & Kali \\
\cline { 3 - 5 } $\mathbf{1}$ & REF & 2 & - & 2 \\
$\mathbf{2}$ & OCR/GFR & 2 & - & 2 \\
$\mathbf{3}$ & OLTC & 1 & - & 1 \\
$\mathbf{4}$ & BHUCOLZT & 1 & - & 1 \\
$\mathbf{5}$ & SHUDDEN PREASURE & 1 & - & 1 \\
$\mathbf{6}$ & PMT 150KV & 1 & - & 3 \\
$\mathbf{7}$ & PMT 20KV INCOMING & 3 & 1 & 1 \\
$\mathbf{8}$ & PMT 20KV FEEDER & - & 1 & 12 \\
\hline
\end{tabular}

(Sumber: Gardu Induk Kalibakal, 2019)

Perhitungan persentase keandalan sistem proteksi pada trafo, hasil perhitungannya pada Tabel 3.4.

Tabel 4. Persentase Keandalan Sistem Proteksi Area Trafo Tenaga Gardu Induk 150 KV Kalibakal Tahun 2012- 2017

\begin{tabular}{|c|c|c|c|c|c|}
\hline \multirow[b]{2}{*}{ No } & \multirow[b]{2}{*}{$\begin{array}{l}\text { Relai Proteksi } \\
\text { Trafo Tenaga }\end{array}$} & \multicolumn{2}{|c|}{ Kinerja Relai Proteksi } & \multirow{2}{*}{$\begin{array}{c}\begin{array}{c}\text { Jumlah } \\
\text { Gangguan }\end{array} \\
\text { Kali }\end{array}$} & \multirow[b]{2}{*}{$\begin{array}{c}\text { Tingkat } \\
\text { Keberhasilan }\end{array}$} \\
\hline & & $\begin{array}{c}\text { Mampu } \\
\text { Mengamankan } \\
\text { Gangguan }\end{array}$ & $\begin{array}{c}\text { Tidak Mampu } \\
\text { Mengamankan } \\
\text { Gangguan }\end{array}$ & & \\
\hline 1 & REF & 2 & - & 2 & $100 \%$ \\
\hline 2 & OCR/GFR & 2 & - & 2 & $100 \%$ \\
\hline 3 & OLTC & 1 & - & 1 & $100 \%$ \\
\hline 4 & BHUCOLZT & 1 & - & 1 & $100 \%$ \\
\hline 5 & $\begin{array}{l}\text { SHUDDEN } \\
\text { PREASURE }\end{array}$ & 1 & - & 1 & $100 \%$ \\
\hline 6 & PMT 150KV & 1 & - & 1 & $100 \%$ \\
\hline 7 & $\begin{array}{l}\text { PMT 20KV } \\
\text { INCOMING }\end{array}$ & 3 & - & 3 & $100 \%$ \\
\hline 8 & $\begin{array}{c}\text { PMT 20KV } \\
\text { FEEDER }\end{array}$ & - & 1 & 1 & $0 \%$ \\
\hline & Jumlah & 11 & 1 & 12 & $91,67 \%$ \\
\hline
\end{tabular}

\subsection{Analisis Gangguan dan Kinerja Sistem Proteksi Transformator}

Gangguan yang timbul dapat di diklasifikasikan menjadi 3 jenis gangguan dimana yang pertama merupakan gangguan teknis, yang kedua gangguan nonteknis serta yang ketiga atau terahir merupakan gangguan yang tidak diketahui penyebabnya. Dengan menggunakan data gangguan tahun 2012 dan rumus analisis deskripsi persentase maka didapatkan persentase gangguan tahun 2012 sebesar 37,5\%.

Halaman Web JRRE : http://jurnalnasional.ump.ac.id/index.php/JRRE 
Data persentase gangguan pada Sistem Proteksi Area Trafo Tenaga Gardu Induk 150 KV Kalibakal Tahun 2012-2017 dalam tabel 2 di atas menunjukkan bahwa persentase gangguan tiap tahun rata-rata sebesar 12.5\%. Persentase gangguan sebesar $12.5 \%$ ini terjadi pada tahun 2015 , 2016, dan 2017, sementara pada tahun 2012 sebesar 37.5\%, tahun 2013 sebesar 25\% dan untuk 2014 tidak terjadi gangguan.

Berdasarkan tabel 3 di atas dapat diketahui kinerja Sistem Proteksi Area Trafo Tenaga Gardu Induk 150 KV Kalibakal dari tahun 2012-2017 temasuk dalam kategori baik. Hal ini dibuktikan dengan sebagian besar gangguan dalam sistem tenaga dapat diatasi, di mana hanya terdapat satu gangguan yang tidak bisa diatasi, yakni gangguan pada PMT $20 \mathrm{KV}$ Feeder.

Suatu relai dikatakan memiliki keandalan baik apabila memiliki keandalan dari $90 \%$ sampai $100 \%$. Untuk menghitung persentase kinerja atau keandalan dari suatu sistem proteksi trafo tenaga, dapat juga menggunakan rumus deskripsi persentaase menggunaan rumus (2), Jadi presentase keandalan relai proteksi trafo 2012-2017 di Gardu Induk 150KV Kalibakal sebesar 91,67\% dan dinyatakan cukup baik karena lebih dari $90 \%$.

\section{KESIMPULAN}

Dari hasil penelitian yang dilakukan di Gardu Induk 150 kV Kalibakal Purwokerto, Banyumas dapat ditarik kesimpulan sebagai berikut:

a. Gangguan yang sering terjadi di Gardu Induk Kalibakal pada tahun 2012-2017 sebanyak 8 kali gangguan dan yang sering mempengaruhi kinerja sistem proteksi trafo adalah gangguan teknis, gangguan non teknis dan gangguan tidak diketahui penyebabnya.

b. Relai proteksi trafo tenaga di Gardu Induk Kalibakal pada tahun 2012- 2017 mempunyai keandalan yang cukup baik mengamankan peralatan dari kerusakan akibat gangguan yaitu sebesar $91,67 \%$.

c. Di Gardu Induk $150 \mathrm{kV}$ Kalibakal dari tahun 2012- 2017 masih ada beberapa gangguan yang tidak di ketahui penyebabnya yang belum dapat di temukan penyebab gangguan.

\section{DAFTAR PUSTAKA}

[1] Ardianto, Firdaus, Noveri L. M. (2017) Analisis Kinerja Sistem Proteksi Berdasarkan Frekuensi Gangguan Di Gardu Induk 150 KV Garuda Sakti. Skripsi. Universitas Riau.

[2] Badruzzaman, Yusnan, dkk. (2014). Keandalan Relai Differential sebagai Pengaman Utama Transformator terhadap Gangguan Arus Hubung Singkat di GIS Randugarut. Jurnal. Politeknik Negeri Semarang.

[3] Polanco, Edgar. (2017). Power Transformer Protection. Skripsi. California State University.

[4] Zhang, Wenkui. (2013). Self-Adaptive Transformer Differential Protection: IET Generation. China.

[5] Suharsimi Arikunto. 2006. Prosedur Penelitian Suatu Pendekatan Praktek: Edisi kelima cetakan ke-13. Jakarta: PT. Rineka Cipta.

[6] Zhang, Wenkui. (2013). Self-Adaptive Transformer Differential Protection: IET Generation. China. 